University of Nebraska - Lincoln

DigitalCommons@University of Nebraska - Lincoln

\title{
Iron supplementation in prevention of severe anaemia and malaria
}

J. Kevin Baird

U.S. Naval Medical Research Institute, jkevinbaird@yahoo.com

Stephen L. Hoffman

U.S. Naval Medical Research Institute

Follow this and additional works at: https://digitalcommons.unl.edu/usnavyresearch

Baird, J. Kevin and Hoffman, Stephen L., "Iron supplementation in prevention of severe anaemia and malaria" (1997). U.S. Navy Research. 74.

https://digitalcommons.unl.edu/usnavyresearch/74

This Article is brought to you for free and open access by the U.S. Department of Defense at DigitalCommons@University of Nebraska - Lincoln. It has been accepted for inclusion in U.S. Navy Research by an authorized administrator of DigitalCommons@University of Nebraska - Lincoln. 
hyperendemic region, Irian Jaya, who received supervised chemoprophylaxis for 1 year in a randomised, placebocontrolled trial. ${ }^{2}$ The post-treatment incidence of $P$ falciparum among men formerly taking chloroquine was twofold higher than among those on daily primaquine or placebo; ${ }^{3}$ this difference $(p=0.03)$ was highest immediately after treatment had been stopped, but tapered to no difference within 12 weeks $(p=0 \cdot 11)$. This magnitude of difference occurred with postprophylaxis anaemia or malaria in the study by Menendez and co-workers. In our study, the protective efficacy of chloroquine during prophylaxis was $33 \%$ compared with placebo $(p=0.50)$, whereas that of primaquine was $94.5 \%$ (95\% CI 57-99). There were no significant between-group differences in the clinical features of first parasitaemia after prophylaxis (frequency of physical complaints, fever, parasite density, and time for clearance of parasitaemia after therapy). We rejected impaired development of natural immunity as an explanation for post-chloroquine rebound of parasitaemia because no rebound occurred among the patients that had taken effective primaquine prophylaxis. $^{2}$ If effective chemoprophylaxis impaired the development of immunity, then a sharp rebound in the primaquine group should have occurred. Our interpretation of the initially higher rate of parasitaemia after chloroquine therapy was the emergence of accumulated subpatent parasitaemias suppressed but not cleared by the drug. A similar process may explain all or part of the findings of Menendez and colleagues.

Another explanation for the postDeltaprim rebound in anaemia may be a selection bias in the post-treatment follow-up groups. In their primary analysis, the investigators included individuals "who had not been withdrawn from the study, and had therefore completed the supplementation scheme (ie, had not been diagnosed as having severe anaemia)". If some children are more susceptible to developing severe anaemia than others, and if these children are also more susceptible to clinical malaria, then they would have been selectively eliminated from the placebo group. By contrast, the children on Deltaprim would have been protected from such a selection process. Thus, the populations compared for post-treatment susceptibility to disease may not be directly comparable. When Menendez and co-workers included individuals with anaemia during the treatment period, the relative risk of post-prophylaxis disease among those who had received the drug fell from $1 \cdot 8$ to $1 \cdot 4$, which reveals a bias towards exaggerated susceptibility in the original estimate.

The post-treatment analyses of Menendez do not link the observed rebound in disease to defects in the development of acquired immunity. Confounding by subpatent parasitaemia or by intrinsic immune differences among survivors of 1 year of treatment versus placebo may explain the post-Deltaprim rebound in disease. Evi-dence of impairment of natural immunity by chemoprophylaxis may have to await development of an immunological test proven to correlate with protective immunity. What Gill ${ }^{4}$ wrote in 1914 still rings true: "Many problems in connexion with malarial immunity would be solved if it were possible to measure directly the degree of immunity possessed by man. Unfortunately, this is at present impossible".

*J Kevin Baird, Stephen L Hoffman

Malaria Program, Naval Medical Research Institute, Rockville, MD 20852, USA

1 Menendez C, Kahigwa E, Hirt R, et al. Randomised placebo-controlled trial of iron supplementation and malaria chemoprophylaxis for prevention of severe anaemia and malaria in Tanzanian infants. Lancet 1997; 350: 844-50.

2 Fryauff DJ, Baird JK, Basri H, et al. Randomised, placebo-controlled trial of primaquine for prophylaxis of falciparum and vivax malaria. Lancet 1995; 346: 1190-93.

3 Fryauff DJ, Baird JK, Purnomo, et al. Malaria in a nonimmune population after extended chloroquine or primaquine prophylaxis. Am f Trop Med Hyg 1997; 56: 137-40.

4 Gill CA. Epidemic or fulminant malaria together with a preliminary study of the part played by immunity to malaria. Indian $\mathcal{F} \mathrm{Med}$ Res 1914; 2: 268-315. 